\title{
INTEGRATED SURVEY FOR TENSIONAL ANALYSIS OF THE VAULT OF THE CHURCH OF SAN NICOLA IN MONTEDORO
}

\author{
D. Costantino ${ }^{1}$, M. Carrieri ${ }^{2}$, A. Restuccia Garofalo ${ }^{2}$, M.G. Angelini ${ }^{1}$, V. Baiocchi ${ }^{3}$, A.M. Bogdan ${ }^{4}$ \\ ${ }^{1}$ DICATECh, Polytechnic of Bari, 70126 Bari, Italy - domenica.costantino@ poliba.it \\ ${ }^{2}$ AESEI s.r.l. Spin Off - Polytechnic of Bari, 74015 Martina Franca (TA), Italy \\ ${ }^{3}$ DICEA, Sapienza University of Rome, I-00184 Rome, Italy - valerio.baiocchi@ uniroma1.it \\ ${ }^{4}$ CCI, Polytechnic University of Timisoara, 300223 Timisoara, Romania
}

KEY WORDS: Laser Scanning, Photogrammetry, UAV, 3D model, tensional analysis

\begin{abstract}
:
This paper presents some of the results obtained from the integrated use of 3D surveying techniques and illustrates some types of analysis and graphic representations that can be conducted and reproduced. The case study concerns the church of San Nicola in Montedoro that is one of the oldest in the city of Martina Franca in the province of Taranto (Italy) and presumably dates back to the fourteenth century. The work consists of a survey with different integrated methodologies, the creation of thematic tables all in order to allow a structural analysis.

The contribution shows how this approach is not intended for a single case study, but starting from it can be extended to other contexts that present similar criticality and potential, often recurrent in the field of the survey and representation of cultural heritage.
\end{abstract}

\section{INTRODUCTION}

Modern surveying technologies in the field of Cultural Heritage offer new perspectives of application both with regard to the acquisition of metric data, and with regard to the processing and subsequent representation and analysis of objects of historical and artistic interest. An essential requirement for the enhancement of a cultural heritage is, in fact, its knowledge in terms of position, form, geometry and structure. The survey is, therefore, the primary moment for the metrical knowledge of the asset.

In the last thirty years we have witnessed the development of digital technologies, which through new instrumentation and methods have allowed us to digitally acquire the geometric information of three-dimensional objects with a good degree of accuracy and resolution.

To date, the panorama of the most widespread solutions and technologies for high-resolution three-dimensional digital surveying in the field of Cultural Heritage includes technologies based on active sensors (range-based), such as laser scanning, and those using passive sensors (image-based), such as high-resolution digital photogrammetry [Blais 2004; Remondino - El Hakim 2006; Guidi et al. 2010; Manferdini Remondino 2010; Vosselman - Maas 2010; Remondino 2011; Pirotti et al. 2013] integrated with automatic image processing methods, such as Structure from Motion [Snavely et al. 2006; Vergauwen - Van Gool 2006; Agarwal et al., 2009; Barazzetti et al. 2010; Del Pizzo - Troisi 2011; Troisi et al., 2017; Alessandri et al.,2019].

The integration of different solutions and technologies is in many cases an approach that can best exploit the potential of the tools depending on the characteristics of the object to be detected and the purposes [Guidi et al. 2002; Velios and Harrison 2002; Böhler and Marbs 2004; El-Hakim et al. 2004; Guidi et al. 2006, Guidi et al. 2009; Callieri et al. 2011; Stocchi et al. 2017].

\section{SAN NICOLA IN MONTEDORO CHURCH}

The church of San Nicola in Montedoro is one of the oldest in the town of Martina Franca in the province of Taranto
(Italy) and presumably dates back to the fourteenth century, the period of Angevin foundation of the city. Located in the Montedoro district, hence "San Nicola di Montedoro". The place is very high and is oriented to the west.

As documented by historian Giovanni Liuzzi in that area already in 1260 stood a castrum martinae, a small fortified settlement with defensive function of the territory of Taranto Murgia on the border with the possessions of Monopoli, a territory almost entirely covered with pastures and forests. At the end of 1200 that castrum was already abandoned and the whole area was included in the orbit of the new town of Martina Franca, which was officially refounded in 1310 by Prince Philip I of Anjou.

The church preserves its original structure, despite the internal transformations of the seventeenth century. Over the centuries the church has undergone several changes, the most significant occurred in the seventeenth century.

The structure is characterized by a modest rectangular hall and late medieval architectural elements visible especially outside. The simplicity of the external facade is embellished only by the roof with raised pitches that intersect and form two gables with cladding made with the typical "chiancarelle". The portal, slightly ogival, is surmounted by a lunette and a small radial rose window, while on the tympanum of the main facade stands a graceful bell tower.

The interior consists of a single room and has two baroque altars in stone. On the walls are visible paintings, made on two layers. Among the saints who can be recognized are St. Nicholas, St. Augustine and St. Scholastica, St. Anthony Abbot, St. Francis of Paola, Our Lady of the Rosary and a Massacre of Innocents.

The institutions responsible for protecting and above all making such an ancient architectural jewel accessible have been absent for years. 


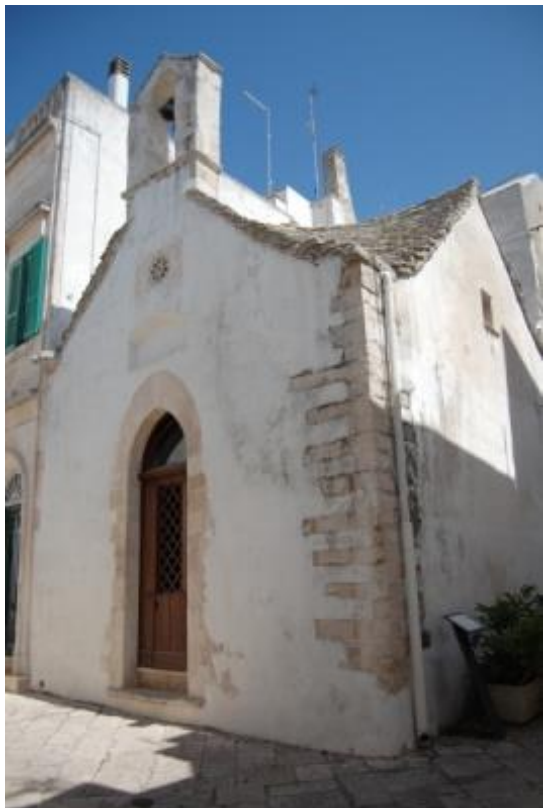

Figure 1. The Church of San Nicola in Montedoro

At the time of the survey activities, the church presented, in fact, structural problems, which mainly concern the vault and consequently the side walls.

\section{INTEGRATED SURVEY}

In order to be able to study the appropriate structural intervention, three-dimensional survey campaigns were started.

In particular, for the interior of the church, since there are also frescoes of great value, and being the same of small size was carried out a campaign of photogrammetric survey by calibrated camera with fisheye lens.

The choice of the fisheye optics represents a possible solution in the survey of narrow spaces in order to reduce the number of shots required. However, the use of this lens requires prior calibration in order to contain the inevitable deformations.

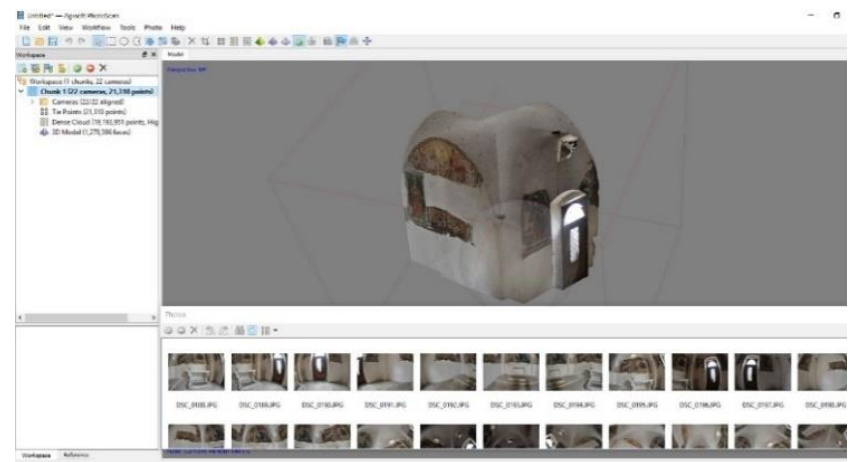

Figure 2. 3D model of the interior of the church.

For the exterior, a laser survey (TLS) was carried out through the construction of three acquisition stations capable of covering the entire external surface of the church. The referencing of the laser scans and of the previous photogrammetric coverage was carried out by means of a topographic survey of support and subsequent georeferencing with GNSS support.

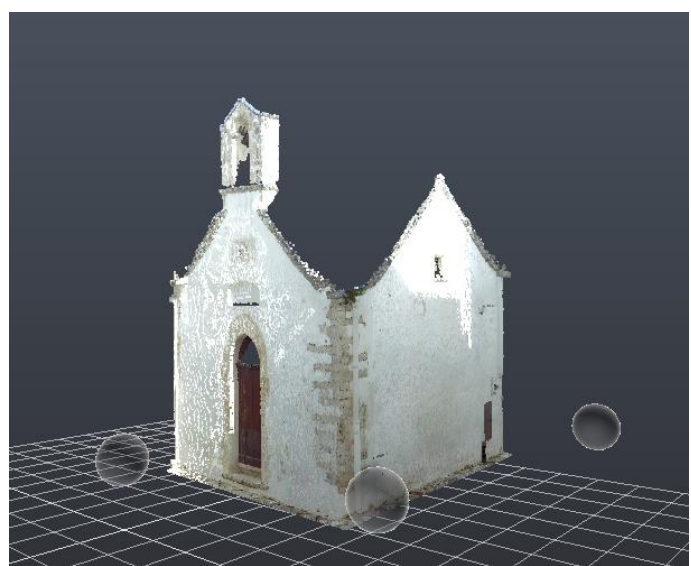

Figure 3. 3D model of the exterior of the church.

The details of the roofing plan of the church were carried out by means of a UAV survey. In particular, the survey was carried out with the Anafi drone by Parrot, which has a low weight (weighs about 320 grams) with the 21-megapixel sensor.

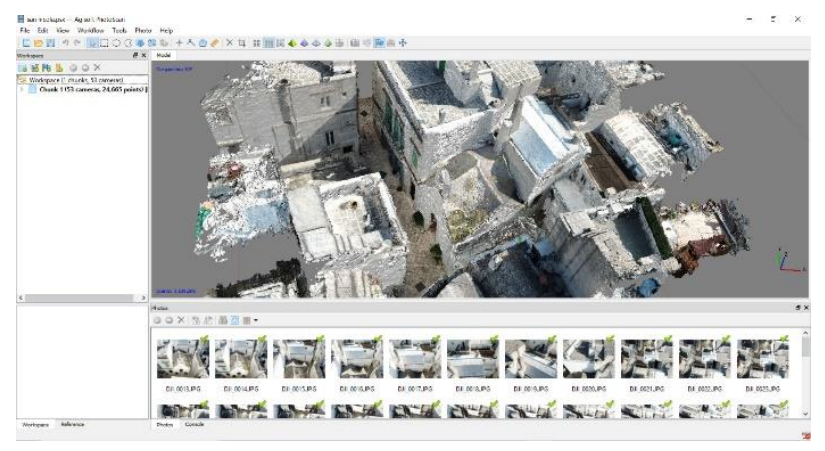

Figure 4. UAV 3D model.

The models obtained were aligned and then geo-referenced plano-altimetrically

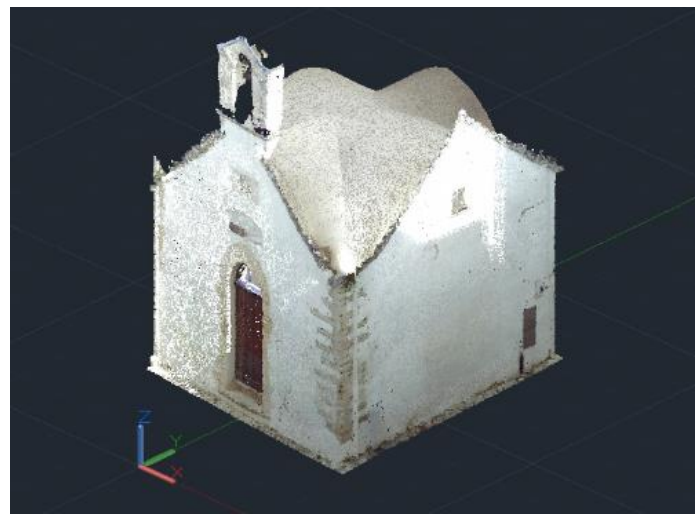

Figure 5. 3D model after alignment.

\section{THEMATIC TABLES}

Thanks to the analysis of the RGB information, a thematic table on the analysis of materials has been drawn up. The aim was to analyse and delimit all materials in the structure. It is a mapping that allowed to group the materials in homogeneous units by nature and characteristics. For each material, the nature, type, dimensions and methods of use were specified. The objective of the thematic table of the analysis of the 
degradation of materials was to detect the various "pathologies" of degradation that have afflicted the building, identifying the causes and mechanisms of deterioration.

This map has been conceived and drawn up as a tool for knowledge and diagnosis and not only as a simple "survey and recording". With reference to the thematic table on the analysis of materials, the state of conservation of each part of the structure was analysed in detail, tracing, for each material, all the phenomena of deterioration and alteration.

The causes of degradation were presented as the sum of the interaction of several degradation actions produced by one or more natural and anthropogenic agents. Other types of degradation mechanisms have also been identified: chemicalphysical and biological.

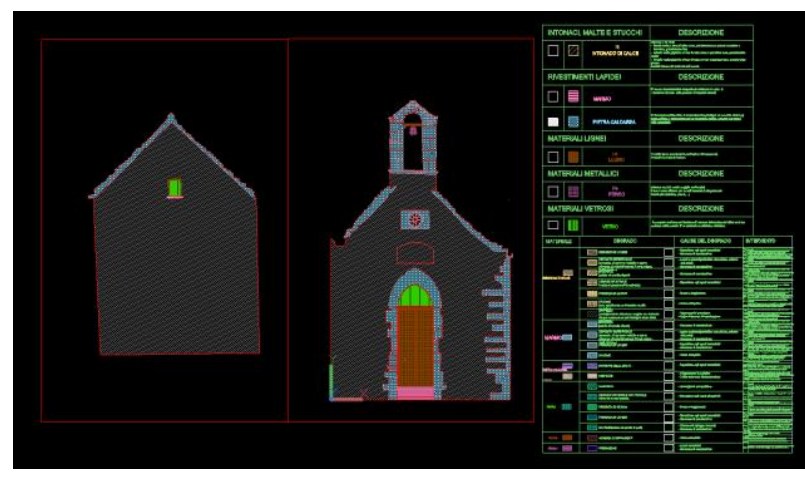

Figure 6. Thematic table on materials analysis

\section{STRUCTURAL ANALYSIS}

The correct relief of the building geometry is a fundamental tool for the knowledge of the structure and for the correct setting of the numerical calculation models. To this end, a survey was carried out that allowed to reach an excellent detail, quantifying also the distortions of the building, and became the basis for the subsequent modeling of the building.

The Church's FEM model required an optimized procedure that, starting from the point cloud, led to a finite element mesh considered adequate for the purposes of the analysis to be carried out.

Starting from the point cloud, two three-dimensional "single line" models were created, respectively in DWG and IGES format, using the two programs autocad and rhinoceros.

The "single line" model consisted of line geometric elements that described, with a great level of detail, the geometry of the Church in terms of edges, thickness changes, openings, vaults, domes and other elements. Subsequently, a further CAD machining was carried out on the single line model, which consisted in rectifying the geometries considered irrelevant for the necessary analyses and arranging geometric inconsistencies such as the non continuity of contiguous lines, for the needs of the subsequent meshing operation. In this phase additional "wires" have been inserted in correspondence of the material discontinuities of the structural elements.

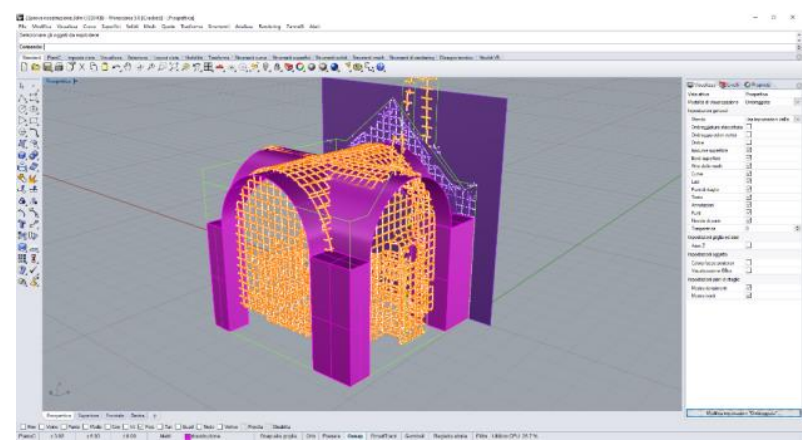

Figure 7. Realization of NURBS, surfaces from the point cloud with Rhinoceros

From the point cloud in the Rhinoceros modeling program, a first 3D model with nurbs surfaces has been created, which can be used as a comparison model with the 3D model for surfaces to be created with MIDAS FX+, a sophisticated surface generation program.
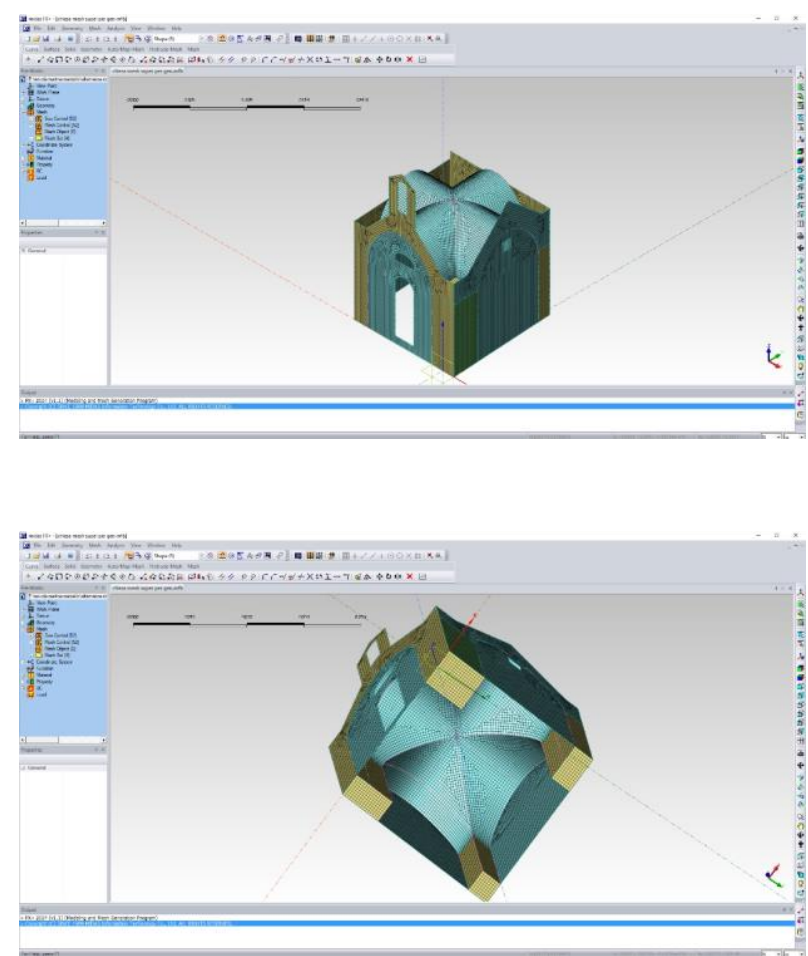

Figure 8. Mesh creation in FX+

Subsequently, the single line model was rectified in MIDAS $\mathrm{FX+}$, and the subsequent meshing with flat finite elements was carried out.

The lines of the single line model, in MIDAS FX+ have been the generators of all surfaces: walls, vaults, domes, etc., constituting walls, vaults, domes, partitioned on the material discontinuities.

The study of the building followed the layout of the GUIDE LINES, proceeding through successive steps of analysis aimed also at checking the reliability of the data of the most complex numerical models:

- Static analysis for vertical loads only, performed with manual calculations to verify the masses in play and the loads in the foundation; 
- Analysis of the first way kinematics (simple tilting, compound, formation of horizontal hinge, expulsion of the cantonal) that constitute, as identified also by the guidelines, the first and main vulnerability of masonry buildings;

- Linear static analysis, to be used as a control element of the order of magnitude of the cutting actions at the base;

- Modal analysis on a global FEM model of the building; once the geometric model was completed and refined, it was imported into the MIDAS GEN calculation software to proceed with the numerical analysis phase $(*)$.

The main modes of vibration show a clear difference in the almost box-like behavior of the lower part of the building (i.e. up to the level of the masonry vault), and the displacements highlighted by the top elements, in particular the façade tympanum.

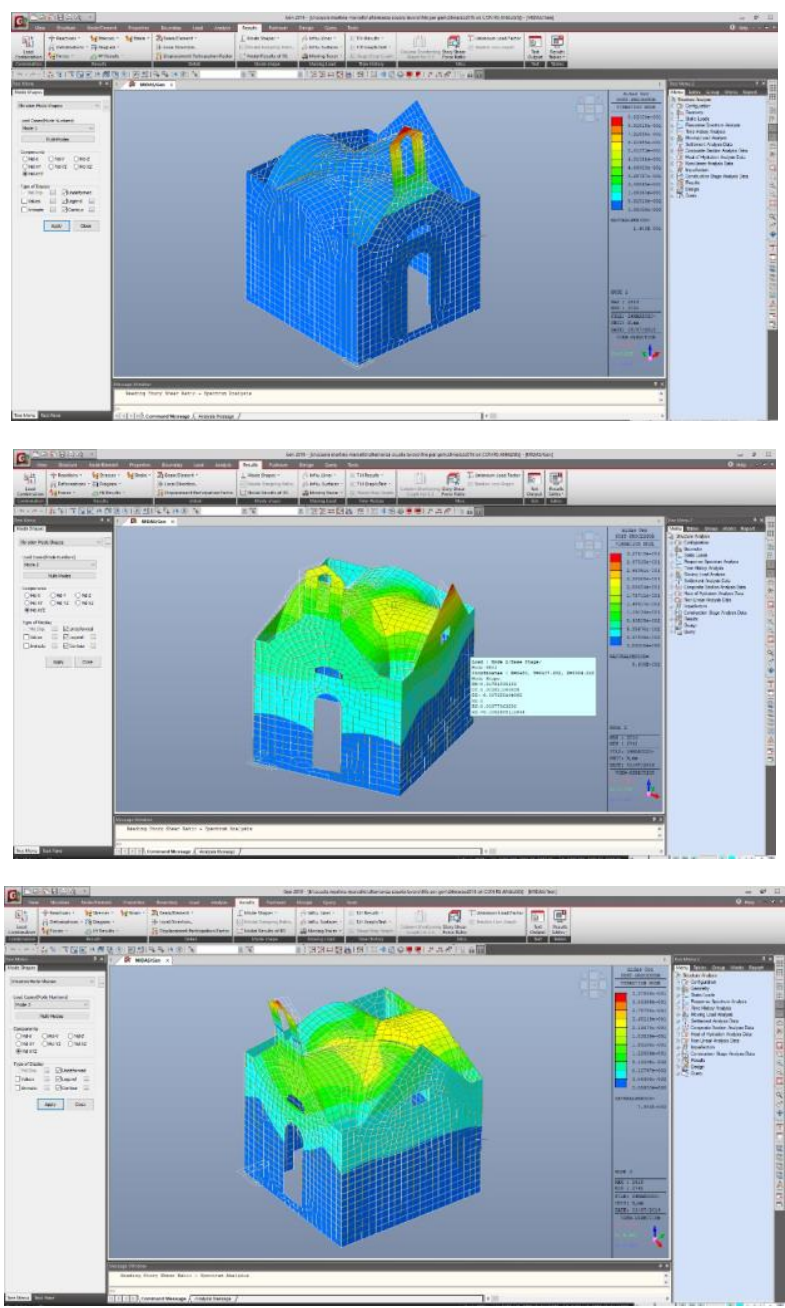

Figure 9. The church's first three ways of vibrating

A reinforcement intervention with chains on the vault was simulated as a reduction of seismic vulnerability.

The non-linearity of the masonry is represented through the adoption of a model of equivalent homogeneous material called strumas, which starts from the definition of a representative elementary volume and different constituent bonds for the three constituent elements (blocks, vertical joints and horizontal joints). Since this is a perfectly plastic elastic bond, the analysis is carried out up to significant shifts, assessing each time the compatibility of the deformed with local crisis phenomena (crisis for cut at $0.4 \% \mathrm{H}$, extraction of the beams, and so on).
A structural reinforcement intervention (the insertion of chains) was also simulated on a vault of the church to contain the thrusts deriving from the own weight, static case, and the horizontal actions, seismic case.
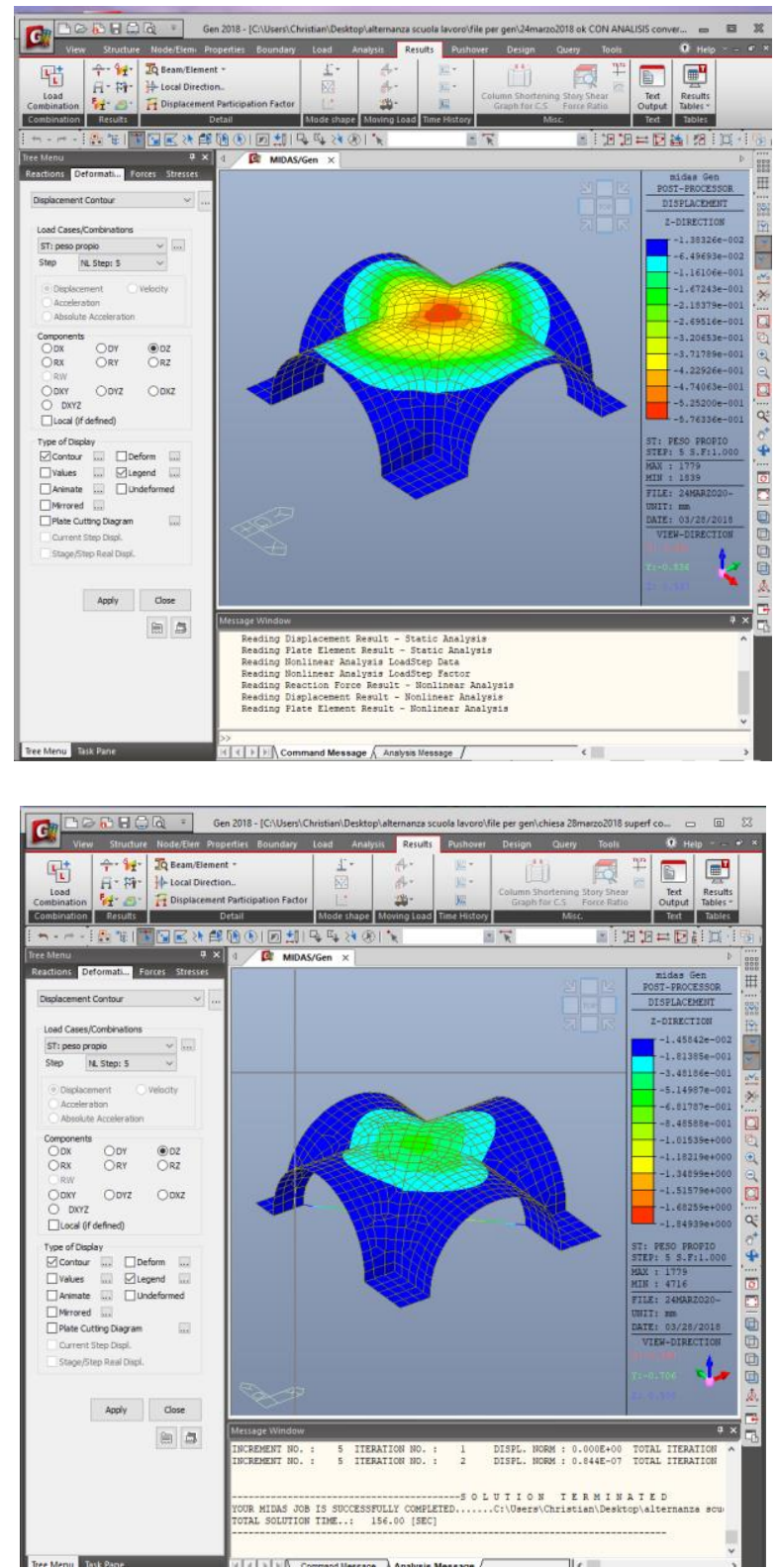

Figure 10. Chain reinforcement effects

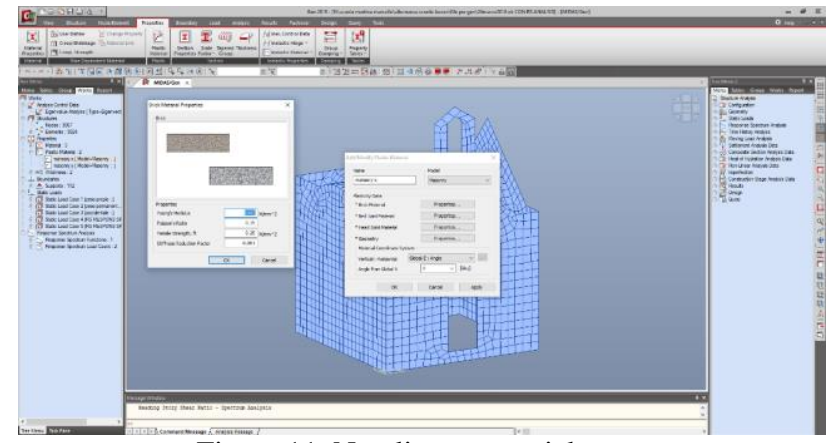

Figure 11. Non linear materials usage 


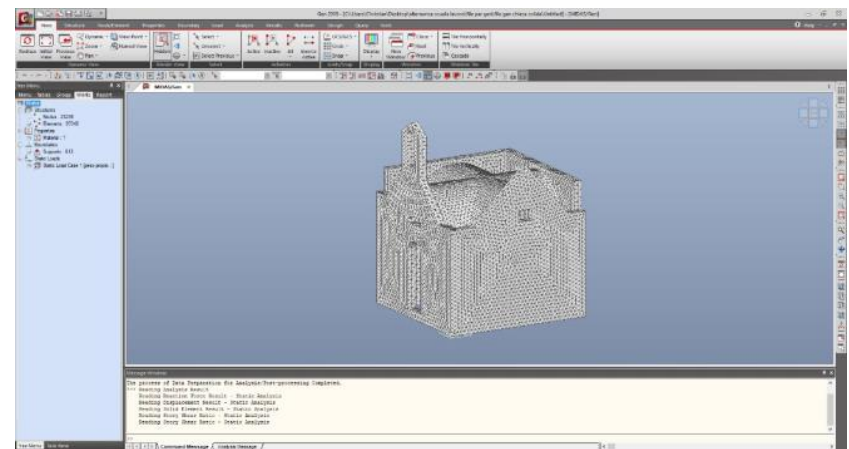

Figure 12. Mesh visualization in calculation software

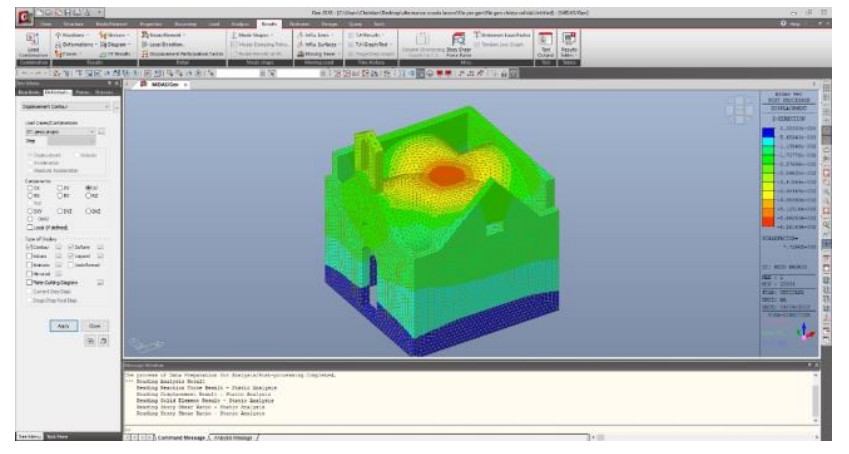

Figure 13. Deformation analysis

\section{CONCLUSIONS}

In the present work, the real feasibility of the integrated use of the latest generation geomatic techniques for the detailed reconstruction of the construction characteristics of a historical building has been verified. The building under study, despite its small size, has nevertheless presented all the characteristics and problems encountered in the survey, restoration and structural study of a historic building. The structural study also made it possible to verify the validity of the reconstruction and the possible exchange of information between the two disciplines.

\section{REFERENCES}

(*) Linee Guida secondo la Direttiva del Presidente del Consiglio dei Ministri 9 febbraio 2011, Valutazione e riduzione del rischio sismico del patrimonio culturale con riferimento alle Norme tecniche per le costruzioni di cui al D.M. 14/01/2008 (pubblicata nella G.U. n. 47 del 26/02/2011 - suppl. ord. n. 54)

Alessandri, L., Baiocchi, V., Del Pizzo, S., Rolfo, M. F., Troisi, S., 2019. Photogrammetric survey with fisheye lens for the characterization of the La Sassa Cave. International Archives of the Photogrammetry, Remote Sensing and Spatial Information Sciences, XLII-2/W9, 25-32, DOI: 10.5194/isprs-archivesXLII-2-W9-25-2019

Angelini, M.G., Baiocchi, V., Costantino, D., Garzia, F., 2017. Scan to BIM for 3D reconstruction of the papal basilica of saint Francis in Assisi In Italy. International Archives of the Photogrammetry, Remote Sensing and Spatial Information Sciences - ISPRS Archives, 42 (5W1), pp. 47-54.

Costantino, D., Angelini, M.G., 2015. Three-Dimensional
Integrated Survey for Building Investigations. Journal of Forensic Sciences, 60 (6), pp. 1625-1632.

Remondino F. \& El-Hakim S., 2006. Image-Based 3d Modelling: A Review. The Photogrammetric Record 21(115), 269-291

Agarwal, S., Snavely, N., Simon, I., Seitz, S. M., Szeliski, R., 2009, Building Rome in a day, in "Proc. of Int. Conference on Computer Vision” Kyoto, Japan, 2009, pp. 1-8.

Barazzetti, L., Scaioni, M., Remondino, F., 2010. Orientation and 3D modeling from marker less terrestrial images: combining accuracy with automation. In The Photogrammetric Record, 25 (132), pp. 356-381.

Böhler, W., Marbs, A., 2004. 3d Scanning and Photogrammetry For Heritage Recording: A Comparison, in "Proc. of the 12th International Conference On Geoinformatics" Gävle, Sweden, pp. 291-298.

Blais, F., 2004. Review of 20 years of range sensor development. In Journal of Electronic Imaging, vol. 13, n. 1, pp. 231-243.

Callieri, M., Chica, A., Dellepiane, M., Besora, I., Corsini, M., Moyés, J., Ranzuglia, G., Scopigno, R., Brunet, P., 2011. Mul tiscale acquisition and presentation of very large artifacts: The case of Portalada. In Journal on Computing and Cultural Heritage (JOCCH), vol. 3, n. 4, pp. 1-14.

Del Pizzo, S., Troisi, S., 2011, Automatic orientation of image sequences in cultural heritag. In Int. Archives of Photogrammetry, Remote Sensing and Spatial Information Science, 38(5/W16), pp. 293-300.

Dellepiane, M., Dell'Unto, N., Callieri, M., Lindgren, S., Scopigno, R., 2013. Archeological excavation monitoring using dense stereo matching techniques. In Journal of Cultural Heritage, vol. 3, n. 14, pp. 201-210.

El-Hakim, S. F., Beraldin, J. A., Picard, M., Godin, G., 2004. Detailed 3d Reconstruction Of Large-Scale Heritage Sites With Integrated Techniques. In IEEE Computer Graphics and Application, vol. 24, n. 3, pp. 21-29.

El-Hakim, Sabry F., Beraldin, J. A., Picard, M., Vettore, A., 2003, Effective 3D Mode ling of Heritage Site, in "Proc. of the 4th International Conference of 3D Imaging and Modeling (3DIM'03)" Banff, Alberta, Canada, pp. 302309.

Graham, L., 2010. Mobile mapping systems overview. In Photogrammetric Engineering \& Remote Sensing, vol. 76, n.3, pp. 222-228.

Guidi, G, Frischer, B., Russo, M., Spinetti, A., Carosso, L., Micoli, L. L., 2006. Three-dimensional acquisition of large and detailed cultural heritage objects. In Machine Vision and Applications, vol. 17, n. 6, pp. 349-360.

Guidi, G., Remondino, F., Russo, M., Menna, F., Rizzi, A., Ercoli, S., 2009. A multi-resolution methodology for the 3D modeling of large and complex archeological areas. In International Journal of Architectural Computing (IJAC), Special issue, pp. 39-55.

Guidi, G., Russo, M., Beraldin J.-Angelo (2010), Acquisizione e modellazione poligonale, McGraw Hill.

Guidi, G., Tucci, G., Beraldin, J.-A., Ciofi, S., Damato, V., Ostuni, D., Costantino, F., El Hakim, S. F., 2002. Multiscale archaeological survey based on the integration of 3D scanning and photogrammetry, in "Int. Workshop on Scanning for 
Cultural Heritage Recording (CIPA WG/6)" Korfu, Greece, pp. 58-64.

Hermon, S., Pilides, D., Amico, N., D’Andrea, Iannone A., Giancarlo G., Chamberlain, M., 2010. Arc3D and 3D laser scanning a comparison of two al ternate technologies for 3D data acquisition, in "Proc. of CAA 2010" Granada, Spain, pp. $55-58$.

Kaartinen, H., Kukko, A., Hyyppä, J., Jaakkola, A., 2012. Benchmarking mobile laser scanning systems using a perma nent test field, in Int. Archives of the Photogrammetry, Remote Sensing and Spatial Information Sciences, XXXIXB5, pp. 471-476.

Incerti, M., 2005. L'Abbazia di Pomposa. Il rilievo 3D per la lettura dei dati geometrico-astro nomici , in "Metodologie innovative integrate per il rilevamento dell'architettura e dell'ambiente. Ricerca COFIN 2002", Gangemi Editore, Roma, pp. 73-76.

Incerti, M., 2005. Procedure e metodiche sperimentali di rilievo mediante 3D laser scanners finaliz zate all'analisi archeoastronomica dell'Abbazia di Pomposa. In Rivista Italiana di Archeoastronomia, III, Quasar Edizioni, pp. 83100.

Manferdini, A. M., Galassi, M., 2013. Assessments for 3d reconstructions of cultural heritage using digital technologies, in Int. Archives of Photogrammetry, Remote Sensing and Spatial Information Sciences, XL-5/W1, pp. 167-174.

Manferdini, A. M., Remondino, F., 2010. Modellazione 3d da immagini. Pipeline fotogrammetrica, in "Modelli digitali 3D in archeologia: il caso di Pompei", Edizioni della Normale, Pisa, pp. 162-199.

Manferdini, A. M., Russo, M., 2013. Multi-scalar 3D digi tization of Cultural Heritage using a low-cost integrated approach, in "Proc. of International Conference on Digital Heritage" Marseille, France, 1, pp. 153-160.

Pirotti, F., Guarnieri, A., Vettore, A.,2013. State of the Art of Ground and Aerial Laser Scanning Technologies for High Resolution Topography of the Earth Surface. In European Journal of Remote Sensing, n. 46, pp. 66-78.

Remondino, F., 2003, From point cloud to surface: the mode ling and visualization problem, in Int. Archives of the Photogrammetry, Remote Sensing and Spatial Information Sciences, 34, 5/W10, pp. 1-11.

Remondino, F., 2011. Heritage Recording and 3D Modeling with Photogrammetry and 3D Scanning. In Remote Sensing, $n$. 3, pp. 11041138.

Snavely, N., Seitz, S., M.; Szeliski, R., 2006. Photo tou rism: exploring photo collections in 3D, in "Proc. of SIGGRAPH'06" Boston, USA, pp. 835-846.

Stocchi, P., Antonioli, F., Montagna, P., (...), Sciortino, R., Pierre, C., 2017. A stalactite record of four relative sea-level highstands during the Middle Pleistocene Transition. Quaternary Science Reviews, 173, pp. 92-100 DOI:10.1016/j.quascirev.2017.08.008

Troisi, S., Baiocchi, V., Del Pizzo, S., Giannone, F., 2017. A prompt methodology to georeference complex hypogea environments. International Archives of the Photogrammetry, Remote Sensing and Spatial Information Sciences - ISPRS Archives 42(2W3), pp. 639-644 DOI: 10.5194/isprs-archives-XLII-2-W3-639-2017
Velios, A., Harrison J.P., 2002. Laser Scanning and digital close range photogrammetry for capturing $3 \mathrm{D}$ archeological objects: a comparison of quality and practicality, in "Proc. of Conference in Computer Applications \& Quantitative Methods in Archaeology (CAA 2011)" Oxford, UK, pp. 205-211.

Vergauwen, M., Van Gool, L., 2006. Web-based 3D re construction service. In Mach. Vis. Appl., vol. 17, n. 6, pp. 411426.

Vosselman, G., Maas, H. G., 2010. Airborne and Terrestrial Laser Scanning 